Session 2125

\title{
K'NEX PROJECT MANAGEMENT EXERCISE: Demonstrating the Importance of Communication
}

\author{
ERIC M. LACHANCE, RONALD W. WELCH \\ United States Military Academy
}

\begin{abstract}
A challenge for most young engineers is the ability to communicate a design, research results or new ideas in a clear concise manner. One technique used at the United States Military Academy (USMA) to demonstrate the importance of communication is the K'NEX Project Management Exercise. The single day exercise navigates students through the entire design process and requires little student preparation. This paper lays out the conduct of the exercise, the results from the exercise as an event at the American Society of Civil Engineers (ASCE) Regional Student Conference and an assessment of the exercise by faculty and students. The feedback shows that an exercise of this nature impresses upon the students the importance of communication in everything they do, especially in their current coursework. The predominant student and faculty recommendation is to use this or a similar type of exercise to not only demonstrate the importance of communication but to provide an excellent model for teaching and assessing the ABET communication skills objective.
\end{abstract}

\section{INTRODUCTION}

The purpose of this paper is to demonstrate how successful role-playing exercises can be in teaching young engineers the importance of communication within the engineering profession. Many engineering scholars and senior managers continue to struggle with the newly trained engineer's inability to communicate effectively research results or a design. Whether this problem stems from simply poor communication skills or the lack of engineering instruction that requires extensive use of communication skills, the engineering education community must develop procedures that improve student communication skills to better serve our client's needs. The primary method of developing engineering communication skills is through design problems. However, design problems are usually evaluated more on the technical aspects of problem solving rather than design communication. As a response to this issue, some engineering programs are adding English professors as adjunct professors to assess/improve student communication skills. One unique technique used at the United States Military Academy (USMA) to demonstrate the importance of communication during an entire project is the K'NEX Project Management Exercise. The entire exercise is built around the standard project design process (see Figure 1: Phases of Project Design ${ }^{1}$ ) with the students focusing on the four primary areas of the process: Design, Contractor Bid, Construction and Load Testing. An additional area added to the process is student self-assessment of their execution of each phase of the project and the overall project.

The following sections focus on the conduct of the exercise and highlight the impact the exercise had on a group of civil engineering students. The presented exercise was validated during the 2001 Upstate New York American Society of Civil Engineer (ASCE) Student 


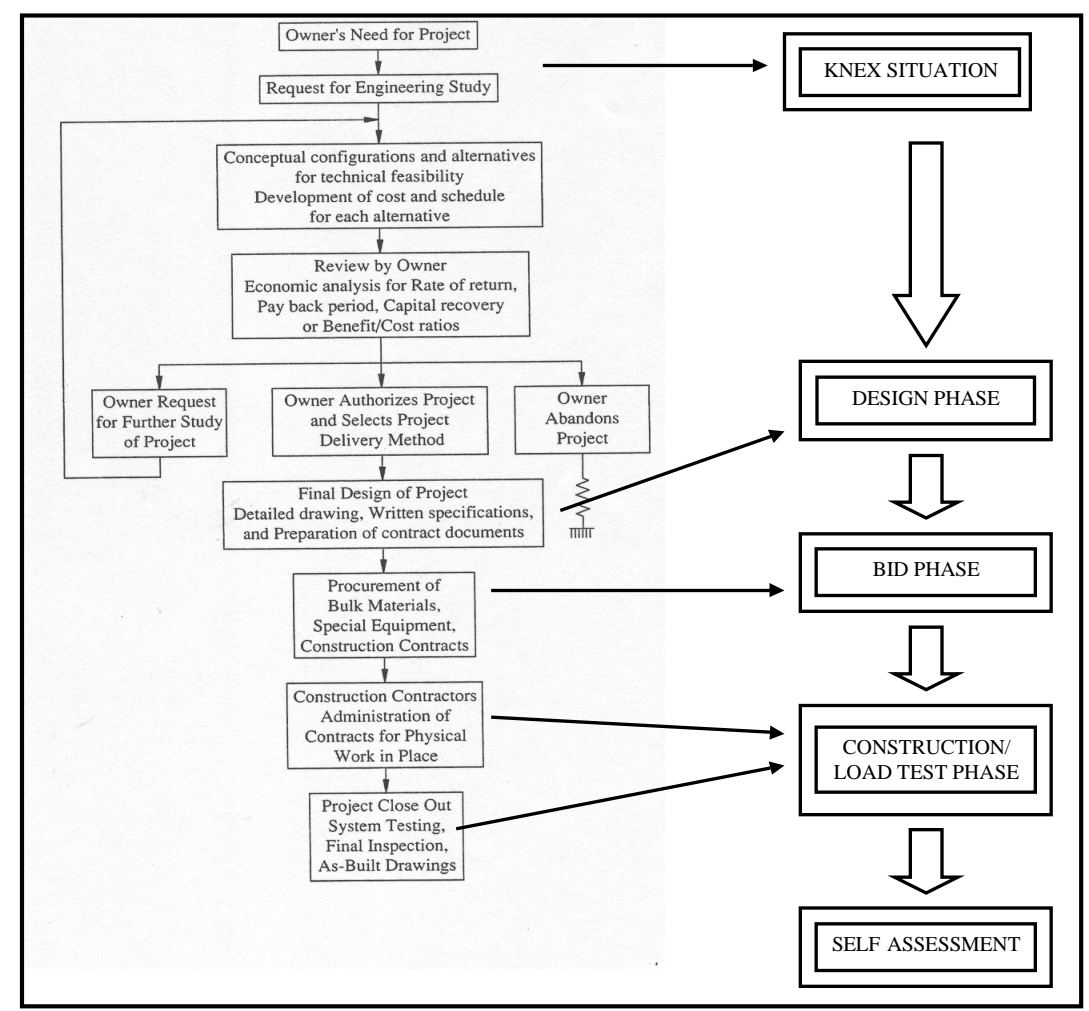

Figure 1: Phases of Project Design

Regional Conference and has been scheduled to be offered at the 2002 ASCE National Conference in Madison, Wisconsin. The exercise demonstrates the fragile link between the

designer, project manager and contractor - a link that is heavily communication driven. The exercise is currently tailored to civil engineers; however, most engineering disciplines can use a similar exercise to demonstrate the importance of clear, concise communication with in any project. A longer, more complex form of the K'NEX exercise is also used during the senior-level seminar course at USMA and is spread over three lessons with additional out of class requirements ${ }^{2}$.

\section{K'NEX SITUATION}

The one-day K'NEX exercise is a "high benefit-low cost" activity. The event consists of a minimum of two, two-person groups per team, an Architect-Engineer (A-E) group and a Construction Contractor Group, who are given a problem they must design (A-E) and then build (Contractor). In the civil engineering exercise, the students design a structure to support a required load. However, the design problem can be easily modified to target most engineering specialties. For the civil engineering exercise, the required materials (see Table 1 - Material Requirements) can be purchased at most toy stores. If K'NEX toys are not available, other building block systems could work. Just evaluate the ability of the connections to support tension/compression loads. K'NEX toy sets are ideal because of the variety of pieces that generally makes it necessary to communicate clearly and precisely and promotes flexibility in the design. During the 2001 conference, students designed a structure (i.e., a crane) to hold a 2$1 / 2$ pound weight cantilevered 18 " over a 24" wall (see Figure $2-$ K'NEX Situation). Within the seminar course at USMA, the students usually design a bridge. However, no matter what the 
Table 1: Material Requirements

\begin{tabular}{|l|r|l|}
\hline ITEM & QTY & NOTES \\
\hline K'NEX Sets & 8 & Enough Materials for ten teams \\
\hline $10 "$ x 10" Sheet of Plywood* & 10 & \\
\hline Stop Watches & 10 & \\
\hline Game Clock & 1 & \\
\hline Tables & 15 & \\
\hline Chairs & 36 & \\
\hline Lap Top Computer & 5 & \\
\hline Calculators & 50 & \\
\hline Gallon Freezor Bags & 3 & \\
\hline Certificates & 50 & \\
\hline Large Rubberbands* & 20 & \\
\hline Manilla Envelopes & 10 & \\
\hline 2 1/2 lb weights* & 10 & \\
\hline C- Clamps* & 10 & \\
\hline 24" High Foam Core Walls* & \\
\hline * Materials For The Given Situation. & \\
\hline
\end{tabular}

engineering students might design, the simple act of requiring the plans to be handed to another group to build will quickly heighten the importance of communication.

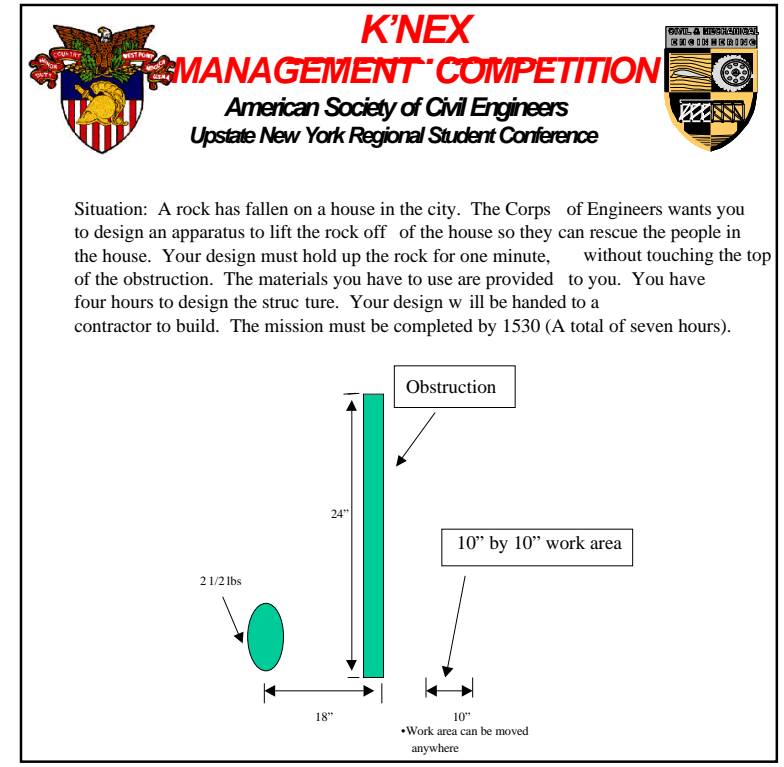

Figure 2: K’NEX Situation

\section{COMPETITION}

\section{a) A-E Design}

The K'NEX exercise starts with the design phase. The A-E group uses their creativity and engineering fundamentals to create a design that meets the owner's intent. The A-E group has a maximum of four hours to design, test (optional) and communicate (write) the plan effectively. In order to provide some realism and replace standard analysis/design tools, the 
event coordinator provides the A-E group the building materials to actually build (optional) the design to test its effectiveness. The assumption is if the students were designing a real structure, they would have appropriate software to assist in the analysis/design. Students are also given the properties of the K'NEX pieces (see Figure 3: K'NEX Design Properties ${ }^{2}$ ) to assist in the actual design. The inherent problem with providing actual K'NEX pieces to the Design Team is that most of the students immediately start connecting pieces rather than performing some simple design calculations on paper, which would keep them from wasting time. A working design is critical; however, it is usually not the only driving force for the engineer.

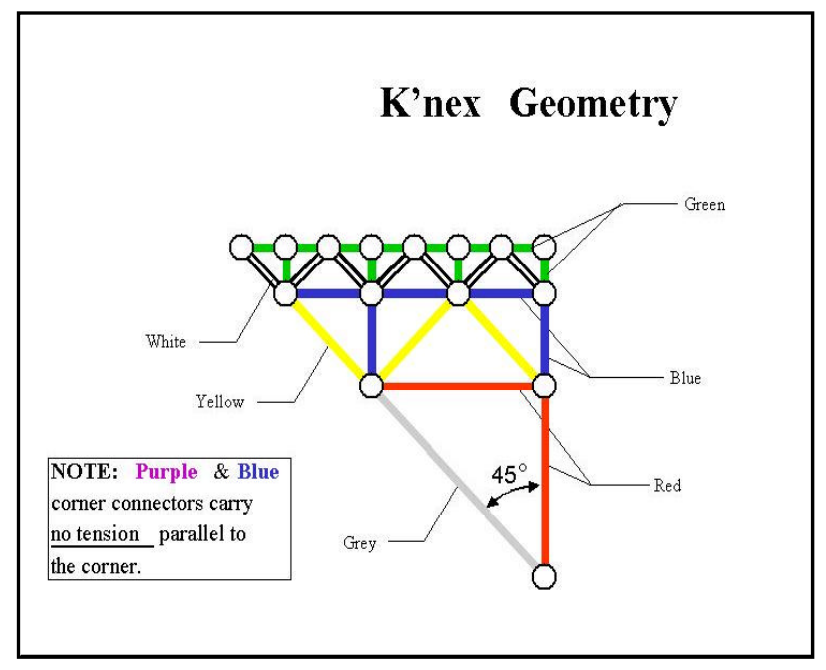

Figure 3: K'NEX Design Properties

The second requirement the A-E group must complete is a cost estimate. Each group is provided a cost sheet to assist in the estimation of construction costs for their structure. The estimate includes the material and labor costs (see Figure Four: Cost Estimate Worksheet ${ }^{2}$ ). Labor costs are calculated using the equation listed at the bottom of the cost estimate worksheet. The estimated time is the number of seconds the A-E group thinks it will take the contractor to build the structure. At the end of this phase, the A-E group provides the plans and cost estimate to the event coordinator in a sealed envelope. Throughout this phase, the contractor group and the A-E group are kept isolated to prevent any communication. The lack of discussion of the plans by groups makes the next phase, bidding, very interesting and very comparable to "real world" bidding situations.

\section{b) Contractor's Bid}

During this phase of the exercise, the contractor must put together a construction estimate using only the written plans provided by the A-E group (i.e., no K'NEX pieces available to proof the design). The contractor has a maximum of one and one half-hours to estimate the quantity of pieces and the necessary time it takes to build the structure (more time is available to complete the estimate if the A-E firm uses less than the maximum four hours to complete the design). The Cost Estimate Worksheet used by the Contractor Group is the same one as the A-E Group (Figure 4). The event coordinator sets a time deadline for the bids to be submitted. If the 
contractor is late with the estimate, they are eliminated from the competition, just like the "real world" bid process.

Once all the bids are in, the event staff conducts a bid opening. All contractors are present to see how their prices compared with their competition. This is the first portion of the exercise to be scored. The most exciting, dramatic part of the event comes during the actual construction and loading.

\section{c) Construction}

The Contractor Group must build the structure and conduct the load test. However, before beginning the actual construction, two activities must occur. First, the Contractor Group decides the size of the labor force. The available labor pool is the entire team - both A-E and Contractor groups. The construction crew does not have to be the same size as provided in the

COST ESTIMATE WORKSHEET

\begin{tabular}{|c|c|c|c|}
\hline ITEM & $\begin{array}{l}\text { *Price } \\
\text { Each }\end{array}$ & $\begin{array}{l}\text { Number } \\
\text { Required }\end{array}$ & $\begin{array}{l}\text { Total } \\
\text { Price }\end{array}$ \\
\hline Green $\operatorname{Rod}\left(5 / 8^{\prime \prime}\right)$ & $\$ 50$ & & \\
\hline White Rod (1-1/4") & $\$ 125$ & & \\
\hline Blue Rod (2-1/8”) & $\$ 215$ & & \\
\hline Yellow Rod (3-3/8") & $\$ 340$ & & \\
\hline $\operatorname{Red} \operatorname{Rod}\left(5-1 / 8^{\prime \prime}\right)$ & $\$ 550$ & & \\
\hline Gray Rod (7-1/2") & $\$ 800$ & & \\
\hline Dark Gray Connector (1 socket) & $\$ 50$ & & \\
\hline Orange Connector (2 sockets) & $\$ 100$ & & \\
\hline Light Gray Connector (2 sockets) & $\$ 100$ & & \\
\hline Red Connector (3 sockets) & $\$ 150$ & & \\
\hline Green Connector (4 sockets) & $\$ 200$ & & \\
\hline Yellow Connector (5 sockets) & $\$ 250$ & & \\
\hline Light Orange Connector (5 sockets + Tab) & $\$ 300$ & & \\
\hline White Connector (8 sockets) & $\$ 350$ & & \\
\hline Purple Corner Connector (4 sockets) & $\$ 250$ & & \\
\hline Blue Corner Connector ( 7 sockets) & $\$ 350$ & & \\
\hline Rubber Bands & $\$ 5,000$ ea. & & \\
\hline Cable & $\$ 1,000 /$ in & & \\
\hline Counter Weight & $\$ 3,000 / \mathrm{lb}$ & & \\
\hline \multicolumn{3}{|c|}{ 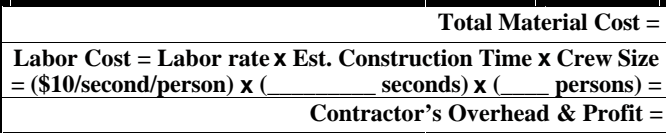 } & \\
\hline \multicolumn{3}{|c|}{ TOTAL ESTIMATED COST = } & \\
\hline
\end{tabular}

* Manufacturer's Suggested Retail Pricє

Figure 4: Cost Estimate Worksheet

Contractor group estimate, but the construction crew must include all the contractor group members before it can include any of the A-E group members (note: the A-E group may have built the model of their design during the design phase). Second, the Contractor receives and inventories the materials ordered when they submitted their estimate. Once the event coordinator and Contractor verify that the ordered materials are present, it is time to begin construction. If the Contractor did not order all the required material to build the structure, they must order the remaining material during the construction phase at a substantially higher cost for rapid delivery. 
The construction phase is timed. The game clock for each team continues until they state that they are completed. Once the event coordinator starts the clock, the contractor can order any materials left out or additional materials required to make the design work once construction issues arise. One team member must fill out an order form and take it to the event coordinator to get the missing/additional materials. This step adds to the total project cost, much like in the real world, in two ways. First, the contractor group member who is ordering materials is pulled away from the team's productivity, thereby adding labor cost. Second, the "During Construction" material cost is on average twenty percent higher than the material costs available during the bidding phase. These additional costs subtlely demonstrate to all the importance of a clear set of plans and specifications. Once the contractor says construction is complete, the clock stops and the A-E group inspects the structure, comparing it to their plans and specifications. The A-E group is only allowed to inspect the final structure, not allowed to load test it. If the A-E says the structure is not satisfactory, the contractor must make the necessary repairs once the event coordinator restarts the game clock, adding more time to the labor cost. Once the A-E approves the structure, it is load tested. The event situation dictates the load testing requirements.

\section{d) Scoring}

The winner is determined using four criteria: lowest contractor bid, largest profit, A-E and contractor bid difference, and the load test. Each one of these is assigned a weight that is multiplied by the place the teams finish in each category (see Figure 5 - Scoring Criteria). The load test value is a function of the number of teams. This generally insures that any team failing

\begin{tabular}{|c|c|c|c|}
\hline Area & Score & Weight & Notes \\
\hline $\begin{array}{l}\text { Contractor's Actual Profit } \\
\text { (Bid - Actual Cost) }\end{array}$ & & .4 & Max is best \\
\hline Lowest Bid & & .4 & Lowest Cost \\
\hline $\begin{array}{c}\text { A/E - Contractor Bid Difference } \\
\text { (A/E Bid - Contractor Bid) }\end{array}$ & & .2 & Least is best \\
\hline Did it Hold Load & $\begin{array}{l}+2 \text { Yes } \\
-1 \text { No }\end{array}$ & $\begin{array}{l}\text { Multiplied by } \\
\text { \# of schools/3 }\end{array}$ & $\begin{array}{l}\text { Hold Load for One } \\
\text { Minute }\end{array}$ \\
\hline
\end{tabular}

Figure 5: Scoring Criteria

the load test will not win. The scoring system was designed to keep the competitors honest and avoid any gamemanship. The evolution of the exercise at USMA has provided confidence in the scoring system presented. Once all the scores from each category are totaled up, the highest score wins.

\section{e) Student Self Assessment}

The critical element to the exercise is for students to learn from their own experiences. The best way to capture these finer points is to conduct a lesson-learned session. The lessons- 
learned are developed in two ways. First, before announcing the winners, the teams fill out a lessons-learned form (See Figure 6 - Lesson Learned Questions). Once each team completes the form, everyone comes together for a discussion on what actually happened. The event coordinator facilitates the discussion by focusing the discussion such that the participants realize the importance of accurate and concise communication. In the exercise scenario, the key areas for discussion are the interpersonal dynamics and clarity of communication between the A-E and the contractor groups. The intent is for the participants to learn from each team's experience.

\section{RESULTS FROM 2001 ASCE STUDENT REGIONAL COMPETITION}

Five teams participated in the 2001 Upstate New York ASCE Student Regional Conference K'NEX Project Management Exercise. The exercise demonstrated to both the civil engineering students and the faculty advisors the importance of quality communication. Observations of the participants during each phase are provided below.

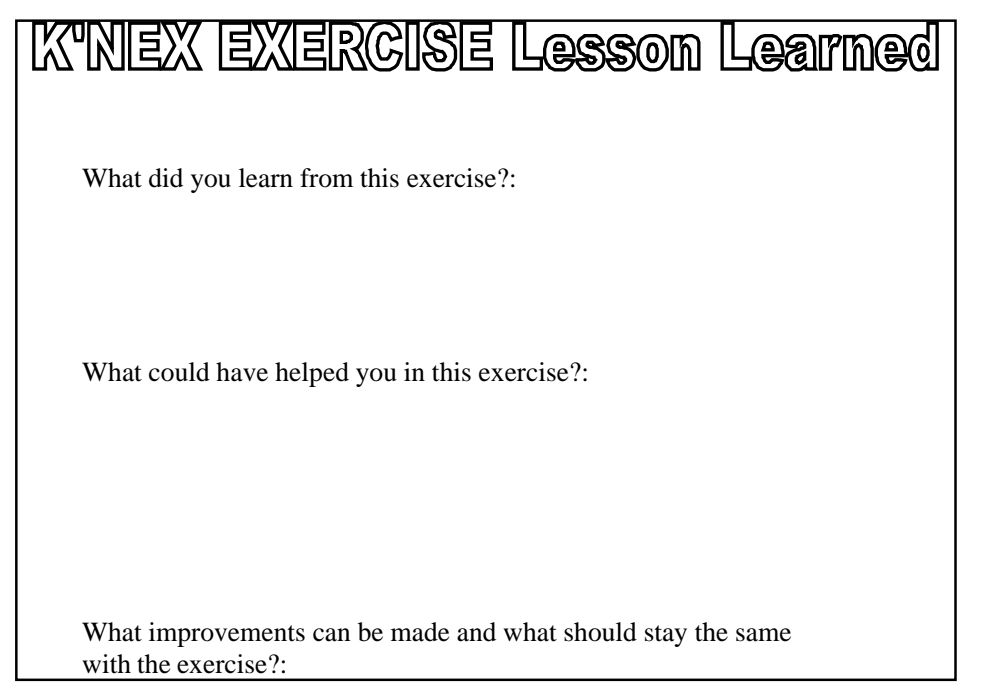

Figure 6: Lesson Learned Questions

\section{a) A-E Design Observations}

During the design phase, the A-E groups took two approaches to the design. The groups that built a successful crane used engineering fundamentals, both statics and mechanics of materials, to develop a design on paper prior to building a working model. The second approach began with the group building first without thinking through the design. Both approaches eventually had to use a trial and error method to fine tune the final design but the teams that began with a paper design had fewer errors to work through to finalize their design.

However, either approach can lead to a poor design as illustrated by four out of five A-E groups not committing enough time to communicate their design. Most A-E groups made many assumptions while transcribing their designs with the most dangerous assumption being that their teammates in the Contractors group would understand their "short-hand" schematics. This caused the Contractors numerous problems during the bid phase. 


\section{b) Contractor Bid Observations}

The most interesting observation made during the exercise by the event coordinators was by watching the Contractors, who have taken the very same courses and in many times are good friends with the A-E group, fail to understand the A-E group's design. In all but one case, the contractors were frustrated by the quality of the plans. Of the five teams that participated, only one, The Players, understood the plans well enough to place an estimate within $10 \%$ of the actual cost or the A-E estimate (Table 2: Final Results). The quality of the drawings provided by the A-E group really caused the contractor problems throughout the estimation process.

Table 2: Final Results

\begin{tabular}{|c|c|c|c|c|c|c|c|c|c|}
\hline $\begin{array}{c}\text { Team } \\
\text { Name }\end{array}$ & \multicolumn{3}{|c|}{$\begin{array}{c}\text { A-E Estimate } \\
\text { (thousands) }\end{array}$} & \multicolumn{3}{c|}{$\begin{array}{c}\text { Contractor Estimate } \\
\text { (thousands) }\end{array}$} & \multicolumn{3}{c|}{$\begin{array}{c}\text { Actual Construction Cost } \\
\text { (thousands) }\end{array}$} \\
\hline & Labor & Material & Total & Labor & Material & Total & Labor & Material & Total \\
\hline The Players & $\$ 36^{*}$ & $\$ 122$ & $\$ 176$ & $\$ 13$ & $\$ 134$ & $\$ 153$ & $\$ 32^{*}$ & $\$ 134$ & $\$ 166$ \\
\hline $\begin{array}{c}\text { The } \\
\text { Buffaloes }\end{array}$ & $\$ 72$ & $\$ 70$ & $\$ 161$ & $\$ 6$ & $\$ 61$ & $\$ 77$ & $\$ 37$ & $\$ 70$ & $\$ 114$ \\
\hline CornWest & $\$ 45$ & $\$ 133$ & $\$ 193$ & $\$ 24$ & $\$ 110$ & $\$ 157$ & $\$ 35$ & $\$ 128$ & $\$ 163$ \\
\hline A-Team & $\$ 48$ & $\$ 171$ & $\$ 230$ & $\$ 108$ & $\$ 160$ & $\$ 196$ & $\$ 53$ & $\$ 195$ & $\$ 248$ \\
\hline $\begin{array}{c}\text { Sander- } \\
\text { Miller }\end{array}$ & $\$ 18$ & $\$ 115$ & $\$ 147$ & $\$ 30^{*}$ & $\$ 132$ & $\$ 172$ & $\$ 31^{*}$ & $\$ 132$ & $\$ 163$ \\
\hline
\end{tabular}

The riskiest part of construction estimating is the cost of labor. It was the same in this exercise as seen by the variances between the actual labor cost and both estimates. Two of the teams (one A-E group and one contractor group) came as close as can be expected for the labor cost (see Table 2 and labor costs marked by asterisks). The variance in labor was primarily due to inexperience with the new material type - K'NEX pieces. An even more significant cost variance was the material costs. Three of the five groups ordered at least $12 \%$, with respect to cost, too few materials. The remaining two groups ordered too much material, approximately $\$ 6,000$ and $\$ 12,000$, and they were not allowed to sell back material, even for a loss, to lower the material costs. The variance in material cost columns (see column 3 and column 6) highlights the importance of quality communication within plans and specifications. Failure to order enough material did not cause problems until the construction phase.

\section{c) Construction}

Every team selected three students as the actual construction force. The contractor had to include its original group of two before any of the A-E group could be included. The contractors all selected an A-E member to help rectify the confusion with their plans. Once the materials were laid out and counted, every team recognized they had not ordered all the materials required.

Therefore, each team had to order additional material during construction. Four out of five teams made the comment that the A-E group assumed the contractor would understand the intent of the plans. They also believed that had the A-E group taken more time to communicate their plan, the team would have been successful. In the end, only two out of five structures held the designated load. The feedback from the students was overwhelmingly positive and to continue this exercise in future competitions. 


\section{d) Student Self Assessment}

Student self-assessments at the completion of the exercise further reinforced the importance of communication in engineering education. For these civil engineering students, the exercise additionally stressed the importance of the designer/contractor relationship to the success of the entire project. The participants had the following comments:

a) Assume nothing when drawing the design-Students with the same course background assumed their plans and specifications showed the critical details. The A-E's left out a large section of the drawings that they assumed the contractor would somehow understand. When the contractor group bid the work, they failed to order all the materials resulting in more expensive materials being ordered during the construction phase, therefore increasing the cost of the project. Each A-E group reviewed their plans at the end of the exercise and realized they had in fact not communicated their plan very well.

b) Engineers spend too much time perfecting the plan but fail to allocate time to properly communicate the design - One team spent far too much time perfecting the plan and not enough time drawing the details. The students' time allocation caused them to hastily sketch the design and the contractors could not properly estimate and build the structure. This is seen in the construction world, as A-E groups fail to spend time communicating the plan and use cut and paste details to finish the drawings on time. The clarity of the plans frustrated many of the contractors. The two groups, A-E and Contractor, within the teams began to develop the stereotypical A-E and Contractor antagonistic relations.

c) Importance of drafting and creativity courses in engineering curriculum - The most surprising student comment concerned the importance of drafting and creativity. During the post-event discussion, the students concurred that drafting skills would have helped greatly with their ability to take a three-dimensional structure, put it on a two dimensional medium and have someone else build it. Expression of creativity was limited by the lack of drafting skills.

d) Importance of engineering fundamentals - The students had to understand basic skills of statics and mechanics of materials for this exercise. Many of the students said they did not consider starting with these key engineering fundamentals because they were just playing with toys. Most realized towards the end of the design stage that these skills are essential and used them to repair structural problem areas.

\section{SUMMARY}

Student feedback emphasized the need for formally taught and continuously developed communication skills in engineering programs. The K'NEX Project Management exercise allows faculty or event coordinators to demonstrate to their students the importance of clear, concise communication of ideas without a large investment of student time or resources. It is recommended that this exercise be implemented in a design course prior to the submission of the capstone design project. ABET engineering program outcome $3(\mathrm{~g})$ is to communicate effectively. It is the responsibility of engineering faculty to produce an engineer who is technically proficient with the ability to communicate effectively. This exercise is one part of the student's academic experience that can help make that goal a reality. 


\section{BIBLIOGRAPHY}

1. Oberlander, G. , Project Management for Engineering and Construction, McGraw-Hill, 2000.

2. Ressler, S., "The Project Management K'nexercise: Using Role-Playing to Facilitate Learning About Design and Construction," Proceedings , 1999 ASEE Annual Conference, ASEE, 1999.

ERIC M. LACHANCE

Major Eric Lachance is an instructor at the United States Military Academy. MAJ Lachance has taught Advanced Structural Analysis and Construction Management. He is the faculty advisor for the ASCE Student Chapter. MAJ Lachance received a BS degree in Construction Management from Arizona State University in 1990 and MS degrees from Stanford University in Civil Engineering, one in Structural Engineering and one in Construction Engineering.

\section{RONALD W. WELCH}

Lieutenant Colonel Ronald W. Welch is an Assistant Professor and Director, Structures Group at the United States Military Academy (USMA). He is a registered Professional Engineer in Virginia. LTC Welch received a BS degree in Mechanical Engineering from USMA in 1982 and MS and Ph.D. degrees in Civil Engineering from the University of Illinois at Urbana-Champaign in 1990 and 1999, respectively. 